\title{
Embodied Collaboration in Small Groups
}

Kellie Williamson and John Sutton

Macquarie University

Email: kellie.williamson@mq.edu.au and john.sutton@mq.edu.au

To appear in Charles T. Wolfe (ed), Brain Theory: essays in critical neurophilosophy (Palgrave Macmillan, 2014).

This is a final draft only, and not identical to the published version.

\section{Introduction: collaboration, teams, and sport}

Being social creatures in a complex world, we do things together. We act jointly. While cooperation, in its broadest sense, can involve merely getting out of each other's way, or refusing to deceive other people, it is also essential to human nature that it involves more active forms of collaboration and coordination (Tomasello 2009; Sterelny 2012). We collaborate with others in many ordinary activities which, though at times similar to those of other animals, take unique and diverse cultural and psychological forms in human beings. But we also work closely and interactively with each other in more peculiar and flexible practices which are in distinctive ways both species-specific and culturally and historically contingent: from team sports to shared labour, from committee work to mass demonstrations, from dancing to reminiscing together about old times.

One such form of collaboration is team sport. Playing with others as part of a team can be a hugely satisfying, stimulating experience. It can also, often simultaneously, be difficult, and fraught with moments where collaboration and coordination break down. The task demands of team sports are challenging and intricate, often pushing players to the limits of their cognitive abilities. Yet even amateur sports teams experience moments, games or seasons when the team works well together. How does such fast-paced, embodied collaboration operate? Consider the corner kick in football. Corner kicks can be an opportunity for both teams to reset their focus, often after a panicked scramble by the defence to stop an attacking raid. For the attacking team, a corner can be an opportunity to implement a series of moves or a set play of which the team has shared knowledge and practiced experience. For the defending team, the pre-occupation is with moving the ball out of the goalmouth and out of danger as quickly as possible. While, descriptively, we can tease out each team's broad aim, the heat of the moment is usually a messier affair. There's typically a flurry of less than calm communication, with defending players, often the goalkeeper, shouting directions, and attackers jostling shoulder to shoulder with defenders vying to be first to the ball. Players must recurrently and effectively switch their focus from their nearby opponents to specific fellow team members and the kicker. Despite this organization and routine, the way a corner kick plays out depends on many small, sometimes game-changing contingencies: how quickly the kick is taken, whether it overshoots the target player or falls short, landing at the feet of a defending player, or whether (on rare but magic occasions) a kicker manages a direct shot on goal that must be defended. The ability to adapt pre-arranged, shared routines to contingencies in the environment lies at the heart of the collective skills involved in a corner kick. In short, the corner kick, a microcosm of the wider complexity found in a football match, demands that teams somehow balance their reliance on pre-prepared 
routines and courses of action with joint, complementary responses to unexpected, fast changes in the world. This takes a dynamic mix of verbal cues, hand signaling, body positioning and role distribution, operating alongside and in conjunction with the teams' response to unexpected error or unexpected movement by an opponent, when there just isn't time for explicit communication. Given such demands and the unruly contingencies of the sporting environment, team sport is a promising research arena for the study of collaborative and coordinated action.

Though the pervasive nature of collaboration in human life is no big news in the social sciences in general, philosophers of mind and cognitive scientists, with their own traditions and preoccupations, have only recently turned in numbers to theorizing and studying such socio-cognitive interactions, asking what kinds of adaptive and shared intelligence are involved in collaborative activities of many kinds. Recent shifts within philosophy of mind and cognitive science have seen many theorists broaden their questions and practices to focus on complex and intricate cognitive and affective processes that spread beyond a single individual's brain - distributed across the body and/or the environment, coopting objects and driving interactions with other individuals. If we follow Robbins and Aydede (2009) in using the label 'situated cognition' as the broadest descriptive category for these new-wave cognitive theories, we can include under its wing a range of distinctive research traditions, with some common ancestry and assumptions but each increasingly developing its own claims and style: work on embodied cognition (Clark 1997; Chemero 2009; Shapiro 2010), enactivism (Varela, Thompson, \& Rosch 1991; Thompson 2007; Di Paolo \& De Jaegher 2012); distributed cognition (Hutchins 1995, 2010a; Kirsh 1995; Sutton 2006) and the extended mind hypothesis (Clark 1997; Clark and Chalmers 1998; Rowlands 1999). These frameworks have drawn attention, in different ways, to the role of activity, the body, external objects, and social interaction in cognition, tracking the cognitive significance of the world beyond the skin and skull. While the approach to studying embodied, skillful collaboration in team sport that we outline here is compatible with many of these streams of research, it is not dependent on any of them. We stress three initial methodological and theoretical points.

First, the extended mind hypothesis, for example, has drawn the attention of researchers to the role that aspects of the environment play in individual cognitive processing, including the kind of cognitive scaffolding that language and tools provide. Until recently, however, the emphasis in philosophical work on the extended mind has been on person-object interactions, including the use of pen and paper, notebooks, human-computer interfaces, iPhones and so on. In contrast, we follow other enthusiasts for socially extended cognition (Wilson 2005; Tollefsen 2006; Hutchins 2010b; Sterelny 2010; Gallagher 2013) in seeking to explore interactions between different people, even when artifacts and objects are also part of the setting or cognitive ecology. In particular, we want to draw attention to the interactions themselves, and the processes that drive joint action between people, rather than the storage and retrieval of single mental states from another person. We advocate doing this via theorizing about real world contexts in which complex, intelligent and skillful collaborative behavior emerges, and drawing on empirical research where data is collected from such contexts, or laboratory methods are adapted to better emulate real world conditions, enhancing what psychologists call their 'ecological validity' (Pinder, Davids, Renshaw, \& Araujo 2011; Barnier 2012). 
Second, work in situated cognition and its subspecies does not, as is sometimes thought, discourage or seek to bypass study of the brain. Rather, as is perhaps clearest in the distributed cognition framework and in the 'second-wave' complementarity-based versions of the extended mind hypothesis (Clark 1997; Sutton 2010), they promote a distinctive kind of 'brain theory'. The functioning of neural systems in humans is unusually plastic and open to influence, heavily reliant on social and cultural resources in both development and mature operation, particularly prone to hook up with and adapt to the peculiar characteristics of the artifacts, institutions, and settings which we have collectively constructed (Clark 2003; Hutchins 2011).

Finally, alongside integration with new movements in cultural neuroscience and neuroanthropology (Chiao 2009; Lende \& Downey 2012), the various schools of situated and embodied cognition therefore need a more sustained focus on real, culturally-embedded skilful bodily practices. Rather than simply mentioning jazz improvisation, circus, dance, or sport as metaphors of or models for dynamic, densely interactive coupling between embodied cognitive agents, or between groups of agents and their tools, standard empirical cognitive science can fruitfully be integrated both with existing rich resources of music, dance, and sport psychology and the kinds of thick description and close analyses of the microprocesses of interaction which are sought in cognitive ethnography (Goodwin 1994, 2013; Hutchins 1995; Enfield \& Levinson 2005; Williams 2006; Sawyer 2007; Streeck, Goodwin, \& LeBaron 2012; Geeves, McIlwain, Sutton \& Christensen 2013). But we retain the ambition of integrating such ethnomethodological detail back into mainstream cognitive theory. The framework we're seeking thus differs clearly both from classical individualist cognitive science, where cognition occurs only in the head of individual thinkers, and from those forms of social theory in which the mind has gone missing entirely, displaced in favour of analyses of ideology or symbolism (as noted also by Downey 2010; Tribble \& Sutton 2012). This particular middle ground is far from empty. But in applying these situated or distributed approaches to skilled movement in small groups, we expand its integrative interdisciplinary reach into distinct areas of both philosophy and psychology.

\section{Recent Treatments of Sport: McGinn and Farrow}

Singling out one domain of independent interest as an instructive case study, we focus especially on research from sports psychology. Sport is an area of sociocognitive and bio-cultural endeavour that is surprisingly underexplored in the cognitive sciences and yet is ripe for investigating human cognition. The bulk of existing research on sport highlights individual expertise alone. In his memoir Sport, for example, Colin McGinn discusses what it is like to play many diverse individual sports, but mentions team sports only in relation to spectators, tribal sentiments, and hero worship. At the heart of skilful sporting experience, for McGinn, is the individual embodied mind, engaged with 'the obliging yet resistant world' or the single 'deadly opponent': the passion for sport derives from 'experiencing yourself as a unity', and from the 'sense of autonomy' gained in 'pleasant existential aloneness', the 'muscular solipsism' of 'a singular being, with my own force and will' (McGinn $2008,2,38-40,117)$. The fact that people often play sport with others, as well as against them, others disappears in McGinn's treatment. Similarly, the majority of experimental research on skill acquisition in sport has focused on individual sports performance. This research is well developed, with a variety of established and robust experimental paradigms aimed at identifying the psychological characteristics of elite 
athletes, including expert patterns of perception, attention, and anticipation (Mann, Abernethy \& Farrow 2010; Muller, Abernethy, Eid, McBean \& Rose 2010), fast decision-making and pattern recognition (Gorman, Abernethy \& Farrow 2011). The research is typically conducted with individual athletes performing a subset of tasks that do not require a real contribution from a team member: for instance, returning a tennis serve, hitting a cricket ball or kicking a football at a video-simulation of a match scenario. Creating scientifically robust tasks that capture real features of competition and performance in sport is an ongoing challenge for sports science. Yet, this corpus of research has made significant progress in understanding how individual elite sportspeople can act swiftly and reliably in difficult, changing contexts.

In contrast, our interests in both sport and embodied minds centre here on cases in which people are not working or moving alone, in which individual participants' unique skills and capacities are merged and coordinated with those of others in service of shared goals. In such cases, sometimes, the experienced unity of successful flowing performance can perhaps be spread or distributed across many people, when the shared, interactive, and often highly pleasurable sense of autonomy which arises among members of an expert team may be quite unlike the existential aloneness of a singular being. While, as an important first step to understanding how teams perform successfully, it is essential to understand the processes that govern individual performance, we seek to push beyond this, to a fuller picture of team skills.

\section{A Tool Kit for Cognitive Collaboration}

While in other contexts we defend the idea that groups or pairs of people may themselves form cognitive systems or group minds (Sutton 2008; Williamson \& Cox 2013; see Theiner, Allen \& Goldstone 2010; Theiner 2013 our focus here is more modest. In constructive rather than critical mode, we sketch elements of a framework for understanding socio-cognitive interactions in teams, taking sports teams as exemplars of collaboration more generally. Collaborative cognition in teams, we argue, is driven by the complex interplay of what, for convenience rather than metapsychological accuracy, we will call higher-level and lower-level processes. Each category, as we use these terms, involves a range of heterogeneous processes that can be usefully grouped together. Higher-level processes are, to a first approximation, the kinds of things that team or group members can talk about: the kinds of processes that can be rendered explicit, as in the use of written or verbal information sharing, or even deliberate, iconic bodily cueing, like pointing or hand waving. These processes can be plans, strategies or instructions made and shared before or after a match, or changed and adapted during play, but they can also include more immediate verbal cues or directions used on the fly to signify an intention or to influence the attention of a team member. In some contexts, they can also include the use of formalized or formalizable game plans, visually represented for instance through diagrams, video footage or on-field/court reenactment. This list is not intended to be exhaustive, but to exemplify the kinds of processes that may be usefully characterized as higher-level.

Lower-level processes are those that are not immediately, easily or perhaps ever able to be tapped by talk. They include gestural, bodily and movement-based forms of information-sharing and cueing, often driven by skillful and honed perceptual and attentional processes. These processes are often thought of as implicit and non-deliberative. They can be fast and adaptive, but they are also developed and 
shaped through practice and performance history. Broadly, lower-level processes are those processes that rely on non-verbal forms of communication and informationsharing: anticipating and responding to the bodily presence of a team member, the direction, speed and shape of a team member's run, the feel and rhythm of the team's movement.

These inclusive labels do not name single unified mental processes, but rather a heterogeneous mix of processes. Each category is internally diverse and complex, as will be reflected in the range of examples falling within each category. The distinction between higher-level and lower-level processes merely offers an initial conceptual framework for tracking the possible modes of interaction that influence a team's performance. We make this distinction partly because different research traditions focus on only one kind of process at the expense of the other. For example, social ontology in philosophy of mind and organizational psychology focuses almost exclusively on higher-level processes, gesturing only in passing at the existence of implicit processes. Similarly, some phenomenological accounts of expertise and skilled performance focus solely on bodily and environmental attunement to the exclusion of higher-level processes (Dreyfus 2007a,b; see Sutton, Mcllwain, Christensen \& Geeves 2011). In contrast, it is the interaction between higher- and lower-level processes that is of intense interest to us, and we stress the dense and complex interplay between them. An appreciation of how such diverse processes interact is essential for understanding how human collaboration is achieved and maintained.

\section{Our Collaborative Lives}

Instances of collaboration and social interaction are abundant in our daily lives, though the two are not coextensive. Sometimes other people are merely external causal influences on individual cognition: a cruel comment from the crowd, for example, can distract a player at a key moment of the match, disrupting performance. Sometimes, in turn, social topics or the skills and characteristics of other people are merely what individuals think about, the content of individual cognitive states: the same player may be motivated to produce a brilliant performance by bringing to mind during the match thoughts or feelings about a particular opponent or mentor. But, we argue, these are not yet cases of collaborative cognition in any substantial sense. Genuinely collaborating, acting and thinking together, performing or reminiscing together, are unlike cases of more accidental social interaction on a number of dimensions (Barnier, Sutton, Harris, \& Wilson 2008; Sutton 2008). While there are domain- and task-based differences across distinctive sorts of joint actions and cognitions, we can also identify some fundamental properties and processes of collaboration that feature in many kinds of joint action. We focus on sports teams in subsequent sections, but first we sketch other examples of the kind of dense interactions that can emerge between two or more people in typical collaborative, socio-cognitive interactions.

One of the most common forms of cognitive collaboration, perhaps surprisingly, is the activity of remembering. It may feel and seem to us that remembering our past experiences is very much an individual experience, where we not only own our memories, but are the sole influence on how our memories are recalled, what it is we remember and what it is we forget. But a large percentage of 
our conversations with others involve reminiscing about our past (Dritschel 1991; Bohanek, Fivush, Zaman, Lepore, Merchant \& Duke 2009). Our own autobiographical memories, in many cases, may be richly shaped not only by the people with whom we share experiences, or those we encode memories with, but also by the people with whom we share, retrieve and reconstruct our memories (Pasupathi 2001; McLean \& Pasupathi 2011). Some memories, while capturing the gist of what took place, seem to be more malleable when recalled in the context of certain listeners (Campbell 2003, 2008) and can be influenced by social factors like conversation norms (Skowronski 2004).

An everyday example is a family remembering together. They might share an experience, and then later spontaneously reminisce together about this experience. It might happen for instance on the way to visit a grandparent, or to a familiar holiday destination, or maybe over dinner or around the television. In these situations different family members may contribute different aspects of the recalled memory: someone might remember when it was, someone else might remember who was there, and someone else might remember that a poignant anecdote now commonly spoken about first surfaced on this particular holiday (Hirst, Manier, \& Apetroaia 1997; Fivush, Bohanek, \& Duke 2008; Shore 2009). There are also more systematic ways that couples or families might remember together, involving complex practices such as using a communal calendar that helps regulate who needs to be where and when, or looking through old photographs together (de Frias, Dixon, \& Bäckman 2003; Brookfield, Brown, \& Reavey 2008; Wu, Birnholtz, Richards, Baecker \& Massimi 2008; Harris, Barnier, \& Sutton 2013; Bietti \& Galiana Castello 2013). Particular family members might also come to be responsible for remembering specific kinds of information such as phone numbers, or the names of distant relations, knowledge of which can be invoked by other family members' requests (Wegner, Giuliano, \& Hertel 1985; Wegner 1987). While remembering together informally differs from forms of collaboration which might arise through formally joining a team or work group, we can get a sense from these cases of the complex ways in which members of a collaborative endeavour subtly interact, shaping and influencing each other's cognition.

Though there certainly are embodied shared processes at play in the above cases (indeed, we suspect that many of the lower-level bodily processes we highlight below would be operative in cases of shared remembering), we move now to cases of movement-driven embodied collaboration, where co-actors must respond to and in concert with each other with their bodies and their movements. Just as a sports team must coordinate their actions efficiently and effectively, so too must a company of modern dancers. Working together and with a choreographer both in the development of a dance and then in performance, dancers must develop and act on a similar understanding of the shared task (Stevens, Malloch, McKechnie \& Steven 2003; Sutton 2005; Kirsh 2013). In rehearsal and preparation, there is time to share and practice, but the mechanisms by which complex bodily skills and movement sequences can be collectively assessed, maintained, transformed, and honed are hard to sustain and thus to study (Kirsh 2011). In performance, there is often no time or opportunity for explicit verbal communication. And because many decisions and intentions are not easily captured by language, there is more demand for different modes of communication between co-actors, including postural and gestural modes of communication. Dancers working together must be sensitive and responsive to each 
other's movements, in some way attuned to each other's decisions and actions. Sensitivity to each other's actions is not merely a social task but also a cognitive task which requires attention, memory, and assessments of when and how to act. The sort of effective collaboration required here involves the interplay of various strategies developed in rehearsal with more in-the-moment processes. In many forms of modern dance, the performance is not the same every time. So while actions planned in prior rehearsal are key, so too are more immediate, synchronic processes that allow the dancers to adapt to novelty or error. In later sections, we canvass the kinds of higherand lower-level processes that interact to sustain embodied, skillful collaborative performance in sport, but we do so in the spirit of using sport as an exemplar of embodied collaboration more generally. We are quietly optimistic that processes similar to those we describe in sporting collaboration may also be efficacious in other kinds of embodied collaboration such as contemporary dance (Sutton 2005).

And finally, working outwards from examples of pairs and families remembering together, and from non-sporting cases of embodied collaborative cognition, we round out these examples by specifying further some of the striking aspects of performance in team sports. The demands sports place on players' perception, action and decision-making capacities are severe, such that successful coordination between team-mates in a team sport is a particularly impressive cognitive feat as well as a sign of the technical and physical prowess of the team members. In team sport players must respond to the often unpredictable behaviour of the opposition, and must anticipate the actions of fellow teammates during an unexpected change in play. Team-mates need to share information about the field of play that cannot be directly accessed by other team members, as when one player has their back to the rest of the field with no time to adjust their position and has no direct visual access to judge the best option for distributing the ball. Similarly, a rugby team must identify the right conditions for a particular set play, and when variations on this set play need to be implemented. Then rapidly and efficiently this decision must be made accessible to other team members. Some of this play will of course depend on each individual's own skills and expertise, but it will also depend on how the teammates interact and share information, both in prior practice and at speed in game time, so as to maximize resources. In cases like these, motivation, cognition, and communication must align to such an extent that it is superfluous to distinguish cognitive, communicative, and social processes. What matters here is identifying key processes that facilitate the collaborative completion of a cognitively demanding task. What are the various higher- and lower-level processes involved? And how do these interact?

Our examples in this section are diverse but not exotic or unusual. They bring to the fore questions and phenomena to guide conceptual and empirical inquiry into cognitive and social coordination, or shared cognition. A plausible framework for explaining thinking and acting with others should accommodate such a diversity of cases. While our focus here is on outlining a broad framework for explaining collaboration in team sport, we are not assuming that all sports are the same, or that all teams or athletes are the same. Instead, we seek out a tool kit to helps us explain how collaboration is achieved while also accommodating the diversity of sports team performance. 


\section{Theorising Higher-Level Processes}

Many sports involve fast-paced, high-stakes tasks, where athletes must act decisively, precisely and often with little time for careful deliberation, acting on-thefly and in the moment. In addition, in team sports athletes are required to co-ordinate their actions, complementing and assisting each other, in the pursuit of a shared goal or aim. It is tempting to theorize sports team behavior solely in terms of implicit, unreportable, non-verbal or deliberative processes where athletes are guided mostly by fast, lower-level processes governed by their direct, present engagement with and attunement to aspects of the task at hand. While in the next section we highlight some examples of lower-level processes, we draw first on literature that emphasizes the higher-level team processes that also constrain and influence a team's behavior. The kinds of higher-level processes we have in mind are deliberative planning and explicit knowledge-sharing processes. For example, game plans devised off the field by coaching staff or players operate as broad sketches of the shape that the team's performance should take including position allocations and tactical options. Plans of this kind are necessarily general, to allow for the details to be filled in in the specific situations that arise through the dynamics of a particular game. Yet these plans can still be extremely subtle, and the subject of intense secrecy, speculation, and analysis. Other forms of higher-level processes might also include specific instructions in the form of verbal feedback from coaches or athletes before, during or after competition and in training contexts. Idiosyncratic verbal cues, code-words or metaphors used by one athlete to another in the heat of the moment are a common means of ensuring that two or more players are making compatible, complementary decisions. Sometimes, for instance, in various football codes, these processes may be formalized through diagrammatic representations of game strategies: such diagrams represent 'plays' or 'moves' by depicting the proposed actions of players in specific positions at specific times, often taking into consideration expected responses from players in the opposing team. To provide some theoretical backing for the observation that planning and explicit knowledge sharing play an important role in sports team performance we can look to organizational psychology and social ontology in the philosophy of mind.

\section{Organisational Psychology}

A common thread of inquiry in organisational psychology characterises group behaviour in terms of information processing (Hinsz, Vollrath \& Tindale 1997). According to this view, groups process information in much the same way as individual cognizers. The focus in this area of research is on what makes a group or a team of people, often co-operating in formal, organized situations, perform successfully and efficiently. Research in this area identifies a mix of cognitive and social factors that interact to drive group performance, including factors that influence group motivation, and the group's capacities to search, attend to, and process select information (Cannon-Bowers, Salas \& Converse 1993; Klimoski \& Mohammed 1994; Eccles \& Johnson 2009). Models of this kind have also been applied to sports teams (Reimer, Park \& Hinsz 2006; Eccles \& Tennenbaum 2007). Many of these models of team processes highlight the importance of shared knowledge across a team (Cannon-Bowers \& Salas 2001; Poizat, Bourbousson, Saury and Sève 2009). The team's ability to compile this shared knowledge over time, access it and update it is essential to the capacity for coordinated action: knowing what to do, and when and with whom to do it. We can speculate that the kind of shared knowledge a sports team needs to have might relate to the sport in general, including knowledge of rules, positions and general success conditions, but also more team-specific knowledge, or 
shared semantic knowledge of team tactics, various players' skills and tendencies. This notion of differential expertise is helpfully captured by David Eccles' notion of division of labor in teams. Working within sports psychology, Eccles draws on constructs from organizational psychology to highlight the importance of both 'sharedness' and also differentiation within groups (Ward \& Eccles 2006). Shared knowledge of the team and the task, he contends, is important for and mediates coordination and collaboration in teams. The knowledge that needs to be shared includes plans, strategies and meaning of idiosyncratic terms and verbal cues (Eccles \& Tenenbaum 2004). As well as shared knowledge, for Eccles, successful groups or teams typically tend to have a decided division of labor between the different group members, often based on heterogeneous expertise in the group (Eccles \& Tennenbaum 2007; Eccles \& Johnson 2009; Wegner 1987). Importantly, for a team to perform successfully, they must be able to co-ordinate this expertise and labor effectively (Eccles 2010). On our framework, this may be achieved through a mix of higher- and lower-level processes, for example, both verbal instructions and game plans and more subtle detection of gestural and bodily cues for team members.

While abstract and conceptual models of information processing in groups are useful for a broad-brush account of the high-level processes in team interactions, there are important questions left unanswered. Specifically, to integrate better with cognitive theory we want to investigate the mechanisms responsible for a group searching for and attending to different information, and updating shared knowledge. Organisational psychology enables us to break down the stages involved in collective information processing, but for a richer framework of collaboration we suggest supplementing specific organizational psychology models with conceptual analysis from social ontology, and evidence of the kind of low-level processes of acting and thinking with an other.

\section{Social Ontology}

Another useful set of conceptual resources for identifying and characterizing higher-level team processes can be found in the area of philosophy known as social ontology. This field deals explicitly with questions of what it is for multiple people acting together to share mental states, and what this means for each individual's mentality. This is an informative area of analysis for our framework because it assists us in carving out what is different, in terms of higher-level processes, for people genuinely acting as part of a team or group or pair, when compared to mere aggregates of individuals who only appear to be acting together: think for example of the differences between walking with a friend or group of friends, and walking alongside unknown people on a street (Gilbert 1990). Where philosophy of mind has a history of considering human mentality as isolated from the social realm (Fodor 1980), social ontology takes sociality and social interaction as its object of philosophical inquiry. We can adapt some of these projects to explore further the cognitive characteristics of people acting together.

For instance, John Searle (1990) argues that the differences between accidental social interaction and genuine collective or collaborative action relate to the intentions involved in the collective action. Genuine collective action, according to Searle, involves collective, shared intentionality, or 'we intentions,' where each participant has an intention to undertake the activity together. Since Searle's early analysis of genuine collaborative activity, theorists have sought to identify the kinds 
of shared mental states that drive genuine collaboration. Margaret Gilbert (1987, 1992) claims that social interaction involves the sharing of mental states between or across multiple individuals. For Gilbert, people who are committed to acting together accrue a set of (non-moral) duties and obligation, including a duty to see through the shared action. For example, members of a sports team are expected to remain members of the team, playing and training together. Unexpected and unexplained departure from the team is not usually met with approval and acceptance by fellow team members (see also Gréhaigne 2011). Gilbert's account highlights the need for each of the individuals acting together to be aware that they are acting with others, and to be mutually aware of the joint nature of their intentions. For our framework, mutual awareness can be plausibly understood as both a social and cognitive phenomenon, relying on social factors such as the distribution of roles across the people acting together, knowing who is to do what and communicating this information between those involved, as well as cognitive factors such as attention to and perception of the behavioural cues of one's co-actors, and joint decision-making.

Michael Bratman builds on the social ontology tradition carved out by Searle and Gilbert, emphasising the interrelatedness of multiple individuals' intentions when acting together. For Bratman, collective or joint action involves an interpersonal structure of connected intentions composed of the intentions of each of the individuals participating in the action (Bratman 1992; Bratman 2009). The way in which the individual's intentions are interrelated is through the 'meshing of subplans.' On Bratman's view, intentions are what guide our planning and preparing for future action. For an action to be joint or collective, and successful, actions must be suitably co-ordinated. So not only does joint or collective action require each person to have a 'we-intention', or an intention that refers to the shared action and the other participant(s): but we must also have compatibility in the way in which the action will be executed, in how our subplans mesh.

While Bratman's focus on the interconnectedness of people who are acting together usefully captures important features of the higher-level processes involved in collaboration, the emphasis on planning and pre-determined courses of action suggests that Bratman's account does not have high-speed collaborative embodied skills as its primary domain of application. Many of our collaborative activities involve spontaneous responses to unpredictable circumstances (Preston 2012) and often coordination is not a matter of planning and verbally communicating those plans. Many team sports, at least in part, require players to innovate and act together in the face of an unpredictable, changing task environment. Sure, part of a team's behaviour is best explained in terms of plans, strategies and set plays including, for example, plans regarding when to bring on particular players from the bench, the enacting of a specific attacking set play in the final moments of a game, or specific verbal cues that tell a team-mate what's about to a happen. And, sure, each player has a we-intention to play together. But there will also be times when error or what the referee or the opposition does disrupts the team's pre-planned strategies. In situations like these the team must rely on other cognitive resources, especially resources that are dynamic and immediate. Explaining this sort of on-the-fly group action in terms of we-intentions and the meshing of subplans does not seem to be the most complete approach. Instead, some sort of combination or interplay between we-intentions and lower levels of information processing may be more likely to drive group or team performance: a dynamic interplay of higher-level and lower-level processes. These 
possibilities are explored in the next section. For our broader framework, analysis from social ontology is useful for teasing out the higher-level processes that are present in collaboration. Ideally, analysis of shared mental states, like we-intentions and shared knowledge, could be usefully integrated with research on lower-level team processes.

The notion of shared or collective mental states (shared intentionality) has received a surprising breadth of empirical treatment in the neuro- and cognitive sciences. Some interesting empirical anchors for the kind of shared or collectively intentionality analysed in social ontology have emerged in recent brain-imaging research. This work lends some credence to the possibility that certain higher-level processes or modes of thinking arising in collaboration have distinctive neural underpinnings. Andreas Roepstorff's research program seeks to develop experimental paradigms for brain-imaging 'mutually interacting minds.' In its early stages, social neuroscience of this kind sees researchers developing new methodologies to try to recreate genuine collaboration in a lab environment with varying degrees of success. Given the manifold of processes that may be operative during collaboration, designing workable, imaging experiments is immensely challenging. Konvalinka and Roepstorff (2012), in a recent review, map some of the difficulties with social neuroscience of this kind, including the design of ecologically valid tasks that can be undertaken in accordance with the restrictions on movement in, for example, fMRI scanning. Early findings include a tendency for the brain rhythms or frequencies of two people to synchronise when undertaking a shared task that requires mutual interaction (Dumas, Nadel, Soussignan, Martinerie \& Garnero 2010); and shifting differences in activation in specific brain regions of interest between senders and receivers of information in turn-taking collaboration (Montague, Berns, Cohen, McClure Pagnoni, Dhamala, Wiest, Karpov, King, Apple \& Fisher 2002). While these studies have limitations (Konvalinka \& Roepstorff 2012), this direction of research suggests a fruitful integration of theoretical approaches to higher-level processes with investigations of neural signatures (Schilbach, Timmermans, Reddy, Costall, Bente, Schlicht \& Vogeley, In press).

A more established example of empirical investigations into the nature of shared intentionality and we-mode thinking is the fascinating research with human children and non-human primates from Michael Tomasello's lab. Tomasello and his school of researchers work with great apes and infants investigating whether, and if so under what conditions, these primates collaborate by way of shared intentionality, or more specifically, shared goals and intentions. On the basis of a vast breadth of research Tomasello and colleagues (Tomasello, Carpenter, Call, Behne \& Moll 2005; Tomasello 2009) argue that while great apes are able to detect intentionality (mental states) in a fellow ape, they do not do so by way of joint intentions or the sharing of mental states. This body of research suggests that we-intentions or we-mode thinking is unique to our species. Great apes seem able to appreciate that others have mental states intentions, such as goals or intentions, but they appear unable to engage in the sharing of these through culturally complex collaboration (Tomasello et al 2005). For example, great apes do not seem able to sustain joint attention. Tomasello and colleagues argue that something other than an understanding that a fellow actor has mental states is required for collaboration, namely, shared intentionality. The relationship between these empirical projects and relevant theorizing about the nature of high-level processes or shared intentionality is an ongoing, difficult project, but is 
all the while making inroads into creating a picture of the cognitive and neural mechanisms that underpin these higher-level process (Gallotti \& Frith 2013).

\section{Finding Lower-Level Processes}

One of the most common observations by sports spectators, commentators and researchers alike, is the speed and intensity at which athletes decide and act in sporting performance - prima facie, in many sporting contexts, there seems to be no time to deliberate on a course of action and then pursue it. As we've suggested, higher-level processes may play a kind of action-constraining or action-guiding role, but it's unlikely they do so without significant facilitation from lower-level processes that are responsive to the specific context in which an athlete or team must act right now. From practitioners' lore, we suspect that gesture or bodily movements and cues are the kinds of things team members are attuned to, and that the information carried by bodies in this way may be used to guide team members' actions. Of course, the specific cues that an athlete attends to may vary depending on the sport: in football, team members may be able to detect information visually from a team member, whereas, in contrast, in team rowing the kinds of information athletes attune to may still be bodily, but may be more likely to be a kind of rhythmic, movement-based information that is felt rather than visually detected (Millar, Oldham \& Renshaw 2012). These kinds of embodied processes have been studied in various disconnected areas of research, but not specifically for sports teams. Empirical research that taps lower-level processes of the kind we're interested in can be very difficult, given that many of these processes operate quickly, automatically and beneath self-report. To get a sense of how existing research might apply to sports teams, we need to be a little inventive in our theorizing. As we noted at the outset, sports science has focused primarily on individual performance, further adding to the need for integrative theorising. To cash out our understanding of possible lower-level team processes we need to borrow again from research outside sport.

The most compelling evidence of the way two or more people interact on the basis of immediate, bodily, automatic processes comes from a branch of research that we can call 'alignment studies' following philosopher Deborah Tollefsen (Tollefsen \& Dale 2012; Tollefsen, Dale \& Paxton 2013). In these studies, the emphasis is on the automatic, unconscious ways in which interacting with others constrains our cognition. 'Alignment' refers to the ways in which two or more people co-ordinate their cognitive and behavioural states, without necessarily trading in fully reportable mental states like intentions or beliefs. When people act together they do so by affecting each other's behaviour across multiple levels of cognitive processing. Implicit and often unreportable cues such as eye gaze patterns, changes in body movement and rhythm, posture and gestures play an important role in facilitating and sustaining successful collaboration. As we will see, processes of alignment are useful for beginning to explain fast-paced joint action such as team sports or spontaneous cooperative action. While more research is needed to fully identify such lower-level processes of alignment in sports performance, there is robust evidence for their existence in cognitive psychology experiments, and as we will see, there are suggestions that this kind of research is possible with sports teams, in a real world setting.

As an example of the kind of alignment processes we are interested in, we take 
a study by the experimental psychologists Richardson and Dale (2005) on the relationship between speakers' and listeners' eye gaze patterns. Richardson and Dale sought to identify to what extent a pair's eye gaze patterns are 'coupled' or constrained by the communication between the two people. Four participants' speech was recorded describing a picture of the cast from a TV series. The remaining thirtysix participants listened to the recordings. Both sets of participants had their eye movements tracked, either while describing the picture or listening to the recorded description, depending on whether one was a speaker or listener. In analysing the patterns of movement, Richardson and Dale found that the pattern of the listeners' eye movements matched the speakers', with a 2 second delay. They further found that the more similar the listener's eye movements were to the speaker's, the better the listener's comprehension of the speaker's speech, when questioned about the content. The significance of this is that the verbal cues provided by one person direct the gaze of the other, constraining what information they attend to. As the speaker was not present when subjects listened to the description, this is good evidence that the verbalisations alone influenced the listener's attention, not gesture or posture. The verbalisations are not just carrying content about the picture but are also playing a role in constraining what the listener attends to. Typically, gaze patterns are not something that we are consciously aware of, so the striking thing about this study is that the actions and cognitions of another person affect one's own cognitive processing beneath conscious awareness. This kind of evidence helps us to build on key concepts from organisational psychology and social ontology by providing evidence of lower-level, automatic ways in which two people can coordinate their behaviour. Where mutual awareness and we-intentions are likely to be reportable, processes of alignment are beneath the level of report, and yet still efficacious in the completion of a shared task. This study is not only striking for the lower-level processes it reveals, but also for the interplay between higher- and lower-level processes that it suggests. The implicit and dynamic process of eye-gaze movement to detect key information in the task environment is constrained and guided by the verbal behaviour of a co-actor. On our characterisation of higher- and lower-level processes, this is an intermeshing of high-level processes adopted by one co-actor, namely verbal descriptions, and lower-level processes adopted automatically and unconsciously by the other co-actor.

In a study more relevant to movement, Richardson and colleagues (Richardson, Marsh, Isenhower, Goodman \& Schmidt 2007) examined the presence of alignment in rocking chair movements. This is more sports-relevant because it deals with co-actors' perception and action mutually influencing each others'. The researchers investigated whether interpersonal coordination would occur between two people, either intentionally or unintentionally, when sitting side-by-side in rocking chairs. In the first experiment, investigating intentional coordination, 24 participants in 12 random pairs were instructed to coordinate their movement. There were two conditions whereby pairs were instructed either to fix their gaze directly ahead, seeing their partner only peripherally, or on the arm rest of their partner's chair. Participants were told to coordinate their rocking either with gaze fixed ahead or on the other's arm rest, depending on which condition they were part of. Surprisingly, Richardson and colleagues found that there was no difference in the stability of coordination between both conditions. This suggests that when coordination is intentional, the information needed to achieve it can be picked up either focally or peripherally.

In order to create as close an analogue to real world social encounters as 
possible, Richardson et al performed the same experiment again, but without instructing the pairs to coordinate their actions. In experiment 2, 16 new participants unknown to each other were assigned randomly to pairs. So as to maintain the coordination's status as unintentional, participants were told that they were testing the ergonomics of the chair and must be tested together to save time. As with the first study there was a focal gaze condition and a peripheral gaze condition, disguised to the participants as a test of postures in the chairs. Participants wore earmuffs to block out auditory cues. Participants in each condition were asked to practice rocking, and they were instructed to ignore their co-participant. It was found that unintentional rocking occurred for those participants who were visually coupled, with participants focusing on each other's arm rest. Coordination, or the synchronising of their movements, was achieved when the movements of the chairs correlated better than chance. This study highlights two important things. The first is that two people can coordinate their actions automatically and without conscious intent. The second is that this is done on the basis of detecting visual information about the others' movements. This is further evidence of lower-level processes by which two or more people can shape each other's actions and cognitions, co-ordinating automatically and swiftly.

We draw now on research in sports psychology as evidence of the kinds of visual information team members are able to detect in perceptually difficult circumstances (Williams \& Ericsson 2005). Kylie Steel and colleagues (Steel, Adams \& Canning 2006) provide evidence to suggest that athletes' perception is attuned to identifying familiar athletes based on minimal information. Working with 15 touch football players, Steel presented the players with $400 \mathrm{msec}$ video clips of people running, whose familiarity to the participants varied from high to low. The footage was created using point-light displays, which meant that most of the distinctive information about the runner was omitted, leaving only the mechanics of their gait as represented by the movement of the point-lights. The runners were a mix of participants' teammates, players from opposition teams and unfamiliar non touch football players. Participants were asked to identify anyone who was familiar, and to rate their certainty. Strikingly, participants were significantly above chance at recognising familiar runners, including teammates and opponent players. This was despite both the short duration of the clips, and the substantial reduction of distinct information. Steele and colleagues replicated this study and its findings with water polo players and their swim stroke (Steel, Adams \& Canning 2007). These findings are very interesting from a collaborative perspective, as they suggest the possibility that team members, over time (though how much time it's not clear), become attuned to specific information from other team members. By combining the evidence from alignment studies that people attune their bodily movement to each other when acting together, with Steel's work, we get a sense of the way that team members use immediate information from other team members (e.g. information about gait or movement style), detected quickly and near automatically (like alignment processes), to collaborate. These are the kinds of low-level processes and mechanisms that contribute importantly to collaboration.

Moving to more fully collaborative sport contexts, we can again look to evidence from sports psychology to provide a hint as to how automatic, lower-level cognitive processes interact with participant's mental states like we-intentions and intermeshed subplans, and with shared knowledge: essentially, the dense interaction between higher- and lower-level processes. With this evidence we can see that 
embodied collaboration involves a complex interplay of a pair's or a group's mental states with moment-to-moment processes. In research conducted with doubles tennis teams, Blickensderfer and colleagues (Blickensderfer, Reynolds, Salas \& CannonBowers 2010) investigated the link between players' previous experience, their shared expectations, and the implicit co-ordination between team members. The construct of 'shared expectations' refers to one domain or sub-set of shared knowledge. Where shared knowledge can span a number of domains including knowledge about the task and about specific team members, long-standing background knowledge, or knowledge that is specific to a given situation (Poizat et al 2009), shared expectations involve knowledge of or team agreement about expected responses from the team. Blickensderfer et al, claim that both shared knowledge and shared expectations are acquired with experience. They predicted that the more experience a team had, the more similar or shared their expectations would be regarding the team's response to match situations. The researchers made the further prediction that the more shared the team's expectations were, the more the team would rely on implicit (non-verbal) coordination rather than explicit, verbal co-ordination. The predicted relationships between these constructs provide a nice test case to suggest how higher-level processes might interact with and shape lower-level processes, namely that forms of shared knowledge can mediate the use of non-verbal communication. Worth noting here though, is that unlike the alignment cases above where the participants were strangers, the participants in this current study have a history of playing together they have had time to build and refine their shared knowledge.

The researchers surveyed 71 high performing teams to ascertain the degree of their task familiarity (years/time spent being coached), team familiarity (years/time playing together), and the extent or degree to which team members shared expectations about team responses to match situations. Shared expectations were measured by players being separately shown drawings of tennis doubles scenes, offered several possible team responses and asked to rate the likelihood that their own team would select each response. The teams' matches were then filmed. Raters of the footage identified the degree of 'relative position' between team members, as a measure of implicit co-ordination. Relative position refers to teammates 'adjust(ing) and adapt(ing) their positioning with respect to each other's positioning during team performance' (Blickensderfer et al 2010). Relative position is akin to the kind of intelligent but fast bodily or positional movement in our football examples, and could equally apply to dancers' movements or to a mother and child re-enacting or recollecting a past experience. Relative position is achieved under severe time constraint and need not rely on overt communication between team members. This is not unlike many mundane cases of collaboration where the action may not be easily verbally communicated due either to time pressures or the difficulty in describing the task linguistically - for example, high-pressure work environments like industrial kitchens or surgical wards. As with some of the alignment evidence, the presence of relative position in this study suggests that more than shared knowledge or weintentions are needed to explain collaboration.

When the survey and video ratings were correlated, Blickensderfer et al found that the degree to which a team had shared expectations about responses to match situations predicted the amount of relative positioning (implicit co-ordination) that the team uses. This suggests that there is a link between higher-level processes like shared knowledge, and lower-level processes like bodily communication or 
information sharing. This study reflects what we have been describing as the interplay between higher- and lower-level processes: in this example, the team's shared knowledge, arising through their history of playing together and available for explicit report, mediates the use of communication processes, enabling a range implicit, nonverbal, bodily forms of communication. Implicit co-ordination here is in some ways akin to what we have been calling lower-level processes. But where our characterisation of lower-level processes differs is that implicit processes are not all mediated by shared knowledge - as we saw with some of the alignment examples, these processes can also operate in the absence of shared knowledge or at least with very minimal shared knowledge, given that alignment can operate among strangers.

This study is a nice example of the possibility that higher-level processes interact with and are mutually shaped by more immediate, lower-level processes. Research of this kind helps to identify the variety of ways in which information can be transmitted amongst team members, and how this information shapes athletes' attention and decision-making. In situations where environmental conditions are changing and unpredictable, such as when faced with a fast-paced opposition, alternate ways of sharing information between teammates, especially through more implicit channels and cues such as body positioning, gestures and movement, may be vital.

\section{Conclusion}

We have characterised collaboration as involving complex and heterogeneous higherand lower-level processes, which are both usually in operation and interaction. In doing this we explored the ways in which different forms of embodied collaboration draw on different kinds of processes, verbal and non-verbal, planned and innovative, to sustain collaboration in tough, cognitively challenging task environments. Drawing on previously disconnected fields of research, we have sought to bring more integrative balance to existing research on collaboration that has often emphasised one kind of process at the expense of the other, thus encouraging a productive engagement between these contributions to our theoretical toolkit. Higher- and lowerlevel processes can be and should be teased out analytically, but their interconnectedness is what we think really drives embodied interactions between team and group members. 


\section{References}

Barnier, A. J. (2012). Memory, ecological validity and a barking dog. Memory Studies, 5(4): 351-359.

Bietti, L.M. \& Galiana Castello, F. (2013). Embodied reminders in family interactions: multimodal collaboration in remembering activities. Discourse Studies $15(5)$

Blickensderfer, E. L., Reynolds, R., Salas, E. \& Cannon-Bowers, J. A. (2010). Shared expectations and implicit coordination in tennis doubles teams. Journal of Applied Sport Psychology, 22(4): 486-499.

Bohanek, J. G., Fivush, R., Zaman, W., Lepore, C. E., Merchant, S. \& Duke, M. P. (2009). Narrative interaction in family dinnertime conversations. Merrill-Palmer Quarterly, 55(4): 488-515.

Bratman, M. E. (1992). Shared cooperative activity. The Philosophical Review, 101(4): 327-341.

Bratman, M. E. (2009). Modest sociality and the distinctiveness of intention, Philosophical Studies, 144(1): 149-165.

Brookfield, H., Brown, S.D. \& Reavey, P. (2008). Vicarious and post memory practices in adopting families: The construction of the past in photography and narrative. Journal of Community and Applied Social Psychology, 18(5): 474-491.

Buszard, T., Farrow, D., \& Kemp, J. (2013). Examining the influence of acute instructional approaches on the decision-making performance of experienced team field sport players. Journal of Sports Sciences, 31(3): 238-247.

Campbell, S. (2003). Relational remembering: Rethinking the memory wars. Lanham: Rowman \& Littlefield.

Campbell, S. (2008). The second voice. Memory Studies, 1(1): 41-48.

Cannon-Bowers, J. A. \& Salas, E. (2001). Reflections on shared cognition. Journal of Organizational Behavior, 22: 195-202.

Cannon-Bowers, J. A., Salas, E. \& Converse, S. (1993). Shared mental models in expert team decision-making. In N. J. Castellan, Jr. (ed.), Individual and group decision making, 221-246. Hillsdale, NJ: Erlbaum.

Chemero, A. (2009). Radical embodied cognitive science. Cambridge: MIT Press.

Chiao, J. Y. (2009). Cultural neuroscience: A once and future discipline. Progress in Brain Research, 178: 287-304.

Clark, A. (1997). Being There: Putting Brain, Body, and World Together Again. Cambridge: MIT Press. 
Clark, A. (2003). Natural-Born Cyborgs: Why Minds and Technologies Are Made to Merge. Oxford: Oxford University Press.

de Frias, C.M., Dixon, R.A., \& Bäckman, L. (2003). Older adults' use of memory compensation strategies is related to psychosocial and health indicators. Journal of Gerontology: Psychological Sciences, 58: 12-22.

Di Paolo, E. and De Jaegher, H. (2012). The interactive brain hypothesis. Frontiers in Human Neuroscience, 6:163.

Downey, G. (2010). 'Practice without theory': a neuroanthropological perspective on embodied learning. Journal of the Royal Anthropological Institute, 16(s1): S22-S40.

Dreyfus, H. L. (2007a). Response to McDowell. Inquiry, 50(4): 371-377.

Dreyfus, H. L. (2007b). The Return of the Myth of the Mental. Inquiry, 50(4): 352365.

Dritschel, B. H. (1991). Autobiographical memory in natural discourse. Applied cognitive psychology, 5(4): 319-330.

Dumas, G., Nadel, J., Soussignan, R., Martinerie, J., \& Garnero, L. (2010). Inter-brain synchronization during social interaction. PloS one, 5(8): e12166.

Eccles, D. (2010). The coordination of labour in sports teams. International Review of Sport and Exercise Psychology, 3(2): 154-170.

Eccles, D. W. \& Johnson, M. B. (2009). Letting the social and cognitive merge. In S. D. Mellalieu \& S. Hanton (eds.). Advances in Applied Sports Psychology, 281-316. London: Routledge.

Eccles, D.W. \& Tenenbaum, G. (2004) Why an expert team is more than a team of experts: A socio-cognitive conceptualization of team coordination and communication in sport. Journal of Sport and Exercise Psychology, 26: 542-560.

Eccles, D. W., \& Tenenbaum, G. (2007). A social cognitive perspective on team functioning in sport. Handbook of sport psychology, 3: 264-286.

Enfield, N. \& Levinson, S. C. (2006) (eds.). Roots of Human Sociality: Culture, Cognition, and Interaction. Oxford: Berg.

Fivush, R., Bohanek, J.G. \& Duke, M. (2008). The intergenerational self: Subjective perspective and family history. In F. Sani (ed.). Individual and Collective SelfContinuity, 131-143. Mahwah, NJ: Erlbaum

Fodor, J. (1980). Methodological solipsism considered as a research strategy in cognitive psychology. Behavioral and Brain Sciences, 3(01): 63-73.

Gallagher, S. (2013). The socially extended mind. Cognitive Systems Research. 
Gallotti, M., \& Frith, C. D. (2013). Social cognition in the we-mode. Trends in Cognitive Sciences.

Geeves, A., McIlwain, D. J., Sutton, J. \& Christensen, W. (2013). To think or not to think: The apparent paradox of expert skill in music performance. Educational Philosophy and Theory, (ahead-of-print): 1-18.

Gilbert, M. (1987). Modelling collective belief. Synthese, 73(1): 185-204.

Gilbert, M. (1990). Walking together: A paradigmatic social phenomenon. Midwest Studies in Philosophy, 15(1): 1-14.

Gilbert, M. (1992). On Social Facts. New Jersey: Princeton University Press.

Gorman, A. D., Abernethy, B. \& Farrow, D. (2011). Investigating the anticipatory nature of pattern perception in sport. Memory \& cognition, 39(5): 894-901.

Goodwin, C. (1994). Professional vision. American anthropologist, 96(3): 606-633.

Goodwin, C. (2013). The co-operative, transformative organization of human action and knowledge. Journal of Pragmatics, 46(1): 8-23.

Gréhaigne, J. F. (2011). Jean-Paul Sartre and team dynamics in collective sport. Sport, Ethics and Philosophy, 5(1): 34-45.

Harris, C. B., Barnier, A. J. \& Sutton, J. (2013). Couples as socially-distributed cognitive systems: An empirical approach. Memory Studies: forthcoming.

Hinsz, V. B., Vollrath, D. A. \& Tindale, R. S. (1997). The emerging conceptualisation of groups as information processors. Psychological Bulletin, 121(1): 43-64.

Hirst, W., Manier, D. \& Apetroaia, I. (1997). The social construction of the remembered self: Family recounting. In J. Snodgrass \& R.Thompson (eds.). The Self Across Psychology, 163-188. New York: New York Academy of Sciences.

Hutchins, E. (1995). Cognition in the Wild. Cambridge: The MIT Press.

Hutchins, E. (2010a). Cognitive ecology. Topics in Cognitive Science, 2(4): 705-715.

Hutchins, E. (2010b) Imagining the cognitive life of things. In L. Malafouris \& C.

Renfrew (eds.). The Cognitive Life of Things, 91-101. Cambridge: McDonald Institute for Archaeological Research.

Hutchins, E. (2011). Enculturating the supersized mind. Philosophical Studies, 152(3): 437-446.

Kirsh, D. (1995). The intelligent use of space. Artificial intelligence, 73(1): 31-68.

Kirsh, D. (2011). Creative cognition in choreography. In Proceedings of the 2nd International Conference on Computational Creativity. 
Kirsh, D. (2013). Embodied cognition and the magical future of interaction design. ACM Transactions On Human Computer Interaction, 20(1).

Klimoski, R. \& Mohammed, S. (1994). Team mental model: Construct or metaphor? Journal of Management, 20:403-437.

Konvalinka, I. \& Roepstorff, A. (2012). The two-brain approach: how can mutually interacting brains teach us something about social interaction?. Frontiers in Human Neuroscience, 6 .

Lende, D. H., \& Downey, G. (2012). The Encultured Brain: An Introduction to Neuroanthropology. Cambridge: MIT Press.

McGinn, C. (2008). Sport. Stocksfield: Acumen Press.

McLean, K. C. \& Pasupathi, M. (2011). Old, new, borrowed, blue? The emergence and retention of personal meaning in autobiographical storytelling. Journal of Personality, 79(1): 135-164.

Mann, D. L., Abernethy, B. \& Farrow, D. (2010). Action specificity increases anticipatory performance and the expert adavantage in natural interceptive tasks. Acta Psychologica, 135(1): 17-23.

Millar, S., Oldham, A. R. \& Renshaw, I. (2012). Interpersonal coupling in rowin: The mediating role of the environment. Journal of Sport and Exercise Psychology, 34(Supp): 110-111.

Montague, P. R., Berns, G. S., Cohen, J. D., McClure, S. M., Pagnoni, G., Dhamala, M., Wiest, M. C., Karpov, I., King, R. D., Apple, N. \& Fisher, R. E. (2002).

Hyperscanning: simultaneous fMRI during linked social interactions. Neuroimage 16: 1159-1164.

Müller, S., Abernethy, B., Eid, M., McBean, R. \& Rose, M. (2010). Expertise and the spatio-temporal characteristics of anticipatory information pick-up from complex movement patterns. Perception, 39(6): 745.

Pasupathi, M. (2001). The social construction of the personal past and its implications for adult development. Psychological Bulletin, 127: 651 -672.

Pinder, R. A., Davids, K. W., Renshaw, I. \& Araújo, D. (2011). Representative learning design and functionality of research and practice in sport. Journal of Sport and Exercise Psychology, 33(1): 146-155.

Poizat, G., Bourbousson, J., Saury, J., \& Sève, C. (2009). Analysis of contextual information sharing during table tennis matches: An empirical study on coordination in sports. International Journal of Sport \& Exercise Psychology, 7: 465-487.

Preston, B. (2012) A Philosophy of Material Culture: Action, Function and Mind. 
Routledge.

Reimer, T. R., Park, E. S. \& Hinsz, V. B. (2006). Shared and coordinated cognition in competitive and dynamic task environments: An information-processing perspective for team sports. International Journal of Sport and Exercise Psychology, 4(4): 376400 .

Richardson, D. C.,\& Dale, R. (2005). Looking to understand: The coupling between speakers' and listeners' eye movements and its relationship to discourse comprehension. Cognitive Science, 29(6): 1045-1060.

Richardson, M. J., Marsh, K. L., Isenhower, R. W., Goodman, J. R. L. \& Schmidt, R. C. (2007). Rocking together: Dynamics of intentional and unintentional interpersonal coordination. Human Movement Science, 26: 867-891.

Robbins, P. \& Aydede, M. (2009) (eds.). The Cambridge Handbook of Situated Cognition. Cambridge: Cambridge University Press.

Rowlands, M. (1999). The body in mind: Understanding cognitive processes. Cambridge: Cambridge University Press.

Sawyer, K. (2007). Group genius. The Creative Power of Collaboration. New York: Basic Books.

Schilbach, L., Timmermans, B., Reddy, V., Costall, A., Bente, G., Schlicht, T., Vogeley, K. (In press). Toward a second-person neuroscience. Behavioral and Brain Sciences.

Searle, J. R. (1990). Collective intentions and actions. In P. Cohen, J. Morgan \& M. E. Pollack (eds). Intentions in Communication, 401-416. Cambridge: The MIT Press.

Shapiro, L. (2010). Embodied cognition. Oxford: Routledge.

Shore, B. (2009). Making time for family: schemas for long-term family memory. Social Indicators Research, 93: 95-103.

Skowronski, J. J., \& Walker, W. R. (2004). How describing autobiographical events can affect autobiographical memories. Social Cognition, 22(5): 555-590.

Steel, K. A., Adams, R. D. \& Canning, C. G. (2006). Identifying runners as football teammates from 400msec Video Clips. Perceptual and Motor Skills, 103: 901-911.

Steel, K. A., Adams, R. D. \& Canning, C. G. (2007) Identifying swimmers as waterpolo or swim team-mates from visual displays of less than one second. Journal of Sports Sciences, 25(11): 1251-1258.

Sterelny, K. (2010). Minds: extended or scaffolded?. Phenomenology and the Cognitive Sciences, 9(4): 465-481.

Sterelny, Kim. (2012). The Evolved Apprentice. Cambridge, MA: MIT Press. 
Stevens, C., Malloch, S., McKechnie, S. \& Steven, N. (2003). Choreographic cognition: The time-course and phenomenology of creating a dance. Pragmatics \& Cognition, 11(2): 297-326.

Streeck, J., Goodwin, C. \& LeBaron, C. (2011). Embodied Interaction: language and body in the material world. Cambridge: Cambridge University Press.

Sutton, J. (2005). Moving and thinking together in dance. Thinking in four dimensions: Creativity and cognition in contemporary dance, 50-56.

Sutton, J. (2006). Distributed cognition: Domains and dimensions. Pragmatics \& Cognition, 14(2): 235-247.

Sutton, J. (2008). Between individual and collective memory: Coordination, interaction, distribution. Social Research: An International Quarterly, 75(1): 23-48.

Sutton, J. (2010). Exograms and interdisciplinarity: History, the extended mind, and the civilizing process. In R. Menary (ed.). The extended mind, 189-225. Cambridge, MA: MIT Press.

Sutton, J., Mcllwain, D., Christensen, W., \& Geeves, A. (2011) Applying intelligence to the reflexes: Emboided skills and habit between Dreyfus and Descartes. Journal of the British Society for Phenomenology, 42(1): 78-103.

Theiner, G. (2013). Transactive memory systems: A mechanistic analysis of emergent group memory. Review of Philosophy and Psychology, forthcoming.

Theiner, G., Allen, C. \& Goldstone, R. L. (2010). Recognizing group cognition. Cognitive Systems Research, 11(4): 378-395.

Thompson, E. (2007). Mind in life: Biology, phenomenology, and the sciences of mind. Belknap Press.

Tollefsen, D. P. (2006). From extended mind to collective mind. Cognitive systems research, 7(2): 140-150.

Tollefsen, D. \& Dale, R. (2012). Naturalizing joint action: A process-based approach. Philosophical Psychology, 25(3): 385-407.

Tollefsen, D. P., Dale, R., \& Paxton, A. (2013). Alignment, Transactive Memory, and Collective Cognitive Systems. Review of Philosophy and Psychology, forthcoming.

Tomasello, M. (2009). Why We Cooperate. Cambridge: Cambridge University Press.

Tomasello, M., Carpenter, M., Call, J., Behne, T. \& Moll, H. (2005). Understanding and sharing intentions: The origins of cultural cognition. Behavioral and brain sciences, 28(5): 675-690.

Tribble, E. B. \& Sutton, J. (2012). Minds in and out of time: memory, embodied skill, 
anachronism, and performance. Textual Practice 26 (4): 587-607.

Varela, F. J., Thompson, E. T. \& Rosch, E. (1991). The Embodied Mind: Cognitive Science and Human Experience. Cambridge, MA: MIT press.

Ward, P. \& Eccles, D. W. (2006). Commentary on "Team cognition and expert team: emerging insights into performance for exceptional teams". International Journal of Sport and Exercise Psychology, 4: 463-483.

Wegner, D. M. (1987). Transactive memory: A contemporary analysis of the group mind. In B. Mullen \& G. R. Goethals (eds.). Theories of Group Behavior, 185-208. New York: Springer-Verlag.

Wegner, D., Giuliano, T. \& Hertel, P. (1985). Cognitive interdependence in close relationships. In W. J. Ickes (ed.). Compatible and Incompatible Relationships, 253276. New York: Springer-Verlag.

Williams, R. F. (2006). Using cognitive ethnography to study instruction. In Proceedings of the 7th International Conference on Learning Sciences, 838-844. International Society of the Learning Sciences.

Williams, M. A. \& Ericsson, K. A. (2005). Perceptual-cognitive expertise in sport: Some considerations when applying the expert performance approach. Human Movement Science, 24: 283-307.

Williamson, K., \& Cox, R. (2013). Distributed cognition in sports teams: Explaining successful and expert performance. Educational Philosophy and Theory, (ahead-ofprint): 1-15.

Wilson, R. A. (2005). Collective memory, group minds, and the extended mind thesis. Cognitive Processing, 6: 227-236.

Wu, M., Birnholtz, J., Richards, B., Baecker, R. \& Massimi, M. (2008). Collaborating to remember: a distributed cognition account of families coping with memory impairments. Proceedings of ACM CHI 2008 conference on human factors in computer systems: $825-834$. 